\title{
El culto a la nación: escritura de la historia y rituales de la memoria en Ecuador, 1870-1950
}

\section{Ana Buriano Castro}

Instituto de Investigaciones Dr. José María Luis Mora, México

Guillermo Bustos, El culto a la nación: escritura de la historia y rituales de la memoria en Ecuador, 1870-1950, Quito, Fondo de Cultura Económica/Universidad Andina Simón Bolívar, Sede Ecuador, 2017.

La fragua de los sentimientos de pertenencia colectiva, la ingeniería política y cultural que permitió la elaboración de imaginarios simbólicos más o menos compartidos, los nacionalismos y la nación fascinaron a la latinoamericanística en confluencia con varios procesos históricos universales que, en las décadas finales del siglo XX, conmovieron la imagen del mundo de posguerra y dispararon la reflexión académica. La nación como "problema” sacudió con altibajos las historiografías y los estudios culturales. La ecuatorianística no se sustrajo a la seducción. La nación fue abordada desde lo político-institucional, desde los proyectos históricos concretos, desde la pintura, la escultura y la literatura, los estudios regionales y desde la construcción historiográfica de ese sujeto elusivo, la nación.

En esa dirección Guillermo Bustos tiene una larga trayectoria y una rigurosa producción diseminada en artículos y capítulos base de una reflexión que, madurada en el tiempo, cimentó esta obra mayor. Emanada de su tesis doctoral en la Universidad de Michigan El culto a la nación ecuatoriana en los ochenta años de tratamiento (1870-1950) es una investigación sólidamente fincada en la historia, pero atravesada por incursiones interdisciplinares. Si bien en esencia la escritura academizada de la disciplina y los rituales 
conmemorativos constituyen el corpus del análisis, todo él está tangencialmente cruzado por un ejemplar tratamiento de la compleja dupla que constituyen la memoria y la historia, la que se encarga de dictar, no sin conflicto y luchas, lo recordable y lo olvidable de nuestros pasados.

El lector se enfrenta a una obra compleja, complejidad que no proviene del tono narrativo fluido, por cierto, sino de la sensación de moverse en múltiples pistas sutilmente conectadas a un tiempo. La excepcionalidad de la propuesta está fundada, sin embargo, en ese entretejido de varias miradas enlazadas por los hilos conductores de la memoria y las conmemoraciones, apoyadas en un sólido entronque teórico-metodológico. Afortunadamente Bustos, con gran manejo del arte, hizo su selección. No toda la representación histórica de la nación está sujeta a escrutinio. A ellas se accede por “ojos de cerradura”: el ámbito discursivo y las prácticas sociales, es decir, las narrativas históricas, la organización discursiva de los metarrelatos y aquellas conmemoraciones que constituyeron puestas en escena de la nación. Para ello conjunta una batería metodológica que le exige incursionar en diversas especialidades: la historia intelectual de la escritura del pasado, la dimensión cultural del proceso de construcción identitaria y los estudios culturales en torno a las conmemoraciones.

Organizada en dos partes, que responden a cortes cronológicos (1870-1909 y 19091950), la obra no se resume en cada una de esas etapas. Tres capítulos informan cada una de las partes en tratamientos paralelos. Los iniciales se abocan al estudio de los primeros grandes metarrelatos históricos elaborados por unos solitarios letrados autodidactas (Pedro Fermín Cevallos y el arzobispo Federico González Suárez), que produjeron narrativas seculares y católicas respectivamente, bajo diferentes contextos de enunciación. Un pasado historiográficamente racializado, un discurso patriótico católico que impregnó el ceremonial laico, a partir del gran peso cultural de la Iglesia, estructuró los rituales conmemorativos de la 
etapa. La inauguración de la estatua de Sucre en 1882, el centenario del nacimiento de Bolívar en 1883 y el primer siglo de vida independiente, en 1909 abrieron un campo de lucha memorística y ritual en torno a los "padres de la patria” que, en su decurso, logró que el culto a la nación migrara del templo a la plaza. Sin embargo, las “condiciones de posibilidad” del discurso, en el sentido foucaultiano, se encargaron de trasladar la sacralidad religiosa a los discursos y rituales seculares, como en una especie de revancha histórica. Consumada la Revolución liberal la conflictiva adquirió una particular configuración en un Estado laico que ejercía su poder sobre una sociedad culturalmente no secularizada. Así la Iglesia hegemonizó la construcción de la memoria nacional.

A modo de un espejo de diferente refracción el nuevo segmento dedicado al periodo comprendido entre la segunda década y la mitad del siglo XX, analiza la institucionalización del saber histórico a través de la Academia Nacional de Historia y su Boletín. Los discípulos del arzobispo-historiador, esos académicos autodidactas asidos al documento, estructuraron la conformación incipiente de un "campo historiográfico" y pugnaron infructuosamente, por la institucionalización del resguardo archivístico de la memoria nacional, a partir de la relación ambigua que establecieron con el Estado que usó el saber de una Academia que no rigió, pero cuya voz legitimó y autorizó en el espacio público. Aunque el hispanismo que impregnó la prosa histórica tiene un extenso seguimiento a lo largo de la obra cobra preeminencia en esta segunda parte, en el análisis de la construcción de una ecuatorianidad donde "la adscripción al paradigma hispanista dependió [...] de que la obtención y uso de la información procedente del archivo colonial se realizara sin alterar el código en que ella fue generada” (p. 273). Esta narrativa histórica emanada de los discípulos del arzobispo (Jacinto Jijón y Caamaño, José Gabriel Navarro y Julio Tobar Donoso) afrontó, desde enfoques diversos, el desafío de hacer 
historia desde un presente conflictivo signado por la pérdida territorial de la Amazonía ecuatoriana, el estallido de descontentos sociales, la irrupción del indigenismo y la revitalización de un panhispanismo acunado por la dictadura franquista.

En ese espacio público complejo las conmemoraciones "en clave hispanista” sobre el cuarto centenario de la fundación de la ciudad de Quito dieron lugar a debates que se sustanciaron en torno a las fechas del aniversario y el sujeto conmemorado (Benalcazar o Almagro) y habilitaron la tímida irrupción de una contramemoria subalterna sobre el también cuarto centenario de un actor silenciado y olvidado en el proceso de construcción historiográfica de la nación: el indio apareció en la no lograda conmemoración de la ejecución de Atahualpa.

Según lo reseñado parecería que en la obra de Bustos la versión académico institucional y la voz estatal ganan la partida. De alguna manera ello es cierto, sin embargo, el autor no desatiende las voces subalternas a las que se asoma desde el apoyo conceptual que le brinda un marco teórico filtrado por los estudios de género, clase y etnia. La atención al Sindicato de Albañiles marcado por el catolicismo social, los periodistas disidentes, la conexión con las instancias gubernativas regionales y las expresiones del indigenismo en auge resultan indicativas de una pluralidad memorística latente. Otra cosa es que esas memorias disidentes no hayan tenido la suficiente fuerza como para impactar los espacios públicos, sembrarlos de monumentos y otros "lugares de la memoria" y aun de imprimir una huella en el relato histórico nacional. Una y mil formas de esas memorias tienen amplia consideración, al punto que rebasan la capacidad analítico-descriptiva de esta reseñadora.

Imposible ignorar el uso fructífero que hace Bustos de un marco teórico-conceptual, de la aplicación rigurosa de conceptos de Certeau, como "operación historiográfica”, de Bourdieu y su teoría de los campos que le permite delinear los contornos del "campo intelectual” de 
escritura de la historia sobre la nación, de muchos subalternistas que introducen riqueza conceptual a un análisis que, por otra parte, recoge los últimos avances de los estudios latinoamericanos en torno a la nación. Todo ello entrelazado por una envidiable apropiación de los estudios sobre la memoria, la identidad nacional y la historia. De Ricour, Nora, Agulhon, Duara, Scott y muchos otros dedicados a dilucidar la "ingeniería social del recuerdo", el estudio de la construcción memorística del pasado ecuatoriano se difumina a lo largo de las más de cuatrocientas páginas, para mostrar la versión hegemónica y triunfante de esa elaboración como una especie de cárcel intelectual y afectiva de larga duración que Bustos reconoce: "El legado de la historia patria nos alcanza en el presente porque todavía, [...] deambulamos en la estructura intelectual que tan exitosamente construyó” (p. 41).

Finalmente, dos inquietudes. A lo largo de la lectura de una obra desbordada de propuestas, de tratamientos en espiral que desaparecen y reaparecen a lo largo del extenso periodo, de estudios que establecen intersecciones problemáticas entre patriotismo, memorias, discurso, ritual conmemorativo y muchas cosas más, el lector ansía el alivio de una conclusión que amarre la problemática construcción de la nación ecuatoriana en esos ochenta años. Encuentra en cambio seis escuetas cuartillas donde Bustos puntualiza la modalidad que adquirió la escritura de la historia y los usos políticos y culturales del pasado de una nación donde el "ethos patriótico” se montó sobre la historia académica y, aunque le imprimió su sello, no logró borrar el carácter “contingente y contencioso” de ese pasado y del presente en el que se labró. Más allá de nuestra aspiración cabe también suponer que el autor no podía, quizás, recurrir a otra solución conclusiva en función de la magnitud de la problemática histórica y las múltiples derivaciones que condensa la obra. 
La inquietud final tiene que ver con la edición. El culto a la nación es la opera prima de la labor editorial de Fondo de Cultura Económica en Quito, en coedición con la UASB. Una correcta caja se inserta en un margen interno inaceptable para la lectura. Apenas dos centímetros más habrían beneficiado la edición. Más allá de ello es de celebrar el esfuerzo editorial y la selección de la obra inaugural, verdadero modelo historiográfico para los estudios sobre la nación latinoamericana. Ojalá este aporte del Fondo contribuya al conocimiento en el continente de las mejores expresiones de la historiografía ecuatoriana y es deseable que los lectores mexicanos podamos acceder a la obra en el medio librero nacional. 